\title{
Fire Retardant Polymer Materials New Perspectives
}

\author{
G. CAMINO \\ Politecnico di Torino, Sede di Alessandria \\ Centro di Cultura per l'Ingegneria delle Materie Plastiche \\ Viale Teresa Michel, 5 - 15100 Alessandria, Italy
}

\begin{abstract}
The reduction of fire risk, defined as the probability of the occurrence of fire and of fire hazard, which concerns the consequences of fires, has become a compulsory requirement for many applications of polymer materials. This most challenging task is affecting the use of a number of the fire retardants that have been instrumental in the exceptional expansion of polymer materials and modern technologies, because they are characterised by low fire risk and high versatility. However, their mechanism of fire retardancy involves potential hazards that are no longer considered acceptable.

New fire retardant strategies are being developed aiming at materials complying with the sustainable development concept. Typically, the approach is shifting from flame extinguishment to flame prevention through flame starvation conditions induced by reduction of the thermal degradation of the polymer that supplies the fuel to the gas phase. In particular a breakthrough could come from chemical-physical processes taking place in the combustion of polymer nanocomposites.
\end{abstract}

KEYWORDS: fire retardants, nanocomposite, sustainability

\section{INTRODUCTION}

Recent events such as the 2004 banning of established fire retardants such as penta- and octa-bromodiphenyl oxides and ongoing fire risk assessment of other commercial fire retardants shows that the quest for environmentally friendly fire retardant polymer materials can no longer be delayed. Moreover, reduction of fire hazard, that is the consequences of fire on people and property, has become as important as reduction of the fire risk, that is the probability of the occurrence of a fire.

The most well established, widely used commercial fire retardants have provided the necessary low fire risk that has allowed the safe development and application of polymer materials for the last fifty years and hence the development of all our technologies in advanced applications as well as in everyday life. However, the "traditional" fire retardants frequently show unsatisfactory performance in terms of environmental impact and fire hazard. Thus, the past fire retardancy strategy mostly aimed at quenching the flame in the gas phase through the supply of radical scavengers, will be largely superceded by condensed phase mechanisms aimed at reducing the supply of combustible gases to the flame, below the self sustaining combustion level.

This choice implies that the mechanism of thermal decomposition of the polymer material must be understood in minute detail to facilitate the design of an effective approach to reduction of volatile flammable degradation products evolving from the exposure of the material to heat from fires. 
A breakthrough in the search for new fire retardant approaches is likely to come from the new generation of polymer materials based on dispersion of nanosized inorganic fillers in the organic matrix in which, for the first time, the improvement of fire retardancy is combined with an improvement of the physical and mechanical properties of the polymer.

\section{GAS PHASE VERSUS CONDENSED PHASE FIRE RETARDANCY - MECHANISTIC APPROACH}

Halogen based, gas phase fire retardants, or chemical inhibitors, which are the most effective and versatile fire retardants developed so far, facilitate flame extinguishment. This is inevitably accompanied by undesirable side effects, such as an increase of smoke obscuration, toxicity and corrosiveness in the gases produced. Indeed, the target of these gas phase fire retardants is a reduction of the rate of thermal oxidation in the flame of the volatile products of the thermal degradation of the polymer. This leads to incomplete oxidation of the organic moieties with formation of large amounts of $\mathrm{CO}$, which alone accounts for most of the toxicity of fire smoke.

Furthermore, chemical species are formed which condense out as finely divided droplets as they exit the highest temperature flame zone combined with carbonised solid particles, giving rise to an obscuring aerosol. Finally, halogenidric acids are evolved which are highly corrosive and affect the integrity of the burning materials jeopardising their function (either structural or otherwise) even in cases of early fire extinguishment. Supertoxic halogenated products can also be formed in the combustion or pyrolysis of aromatic halogenated fire retardants (e.g halogenated dioxins or furans) which make the disposal of fire residues extremely expensive and environmentally hazardous. Similar effects are to be expected in the case of volatile phosphorous based fire retardants which are another available source of effective gas phase flame inhibitor fire retardants.

The early attempt to avoid negative effects of gas phase fire retardancy was based on the use of inorganic hydroxides (e.g., aluminium or magnesium hydroxides) which dehydrate on heating, supplying water vapours to the flame where they act to dilute the combustible volatiles. The rate and heat of combustion may thus decrease below self sustainability. A cooling effect of the condensed phase by the endothermic dehydration reaction also contributes to the overall cooling action. These hydroxides are highly sustainable in that their environmental impact both before, after and during a fire is minimal; but are very poor in terms of fire retardancy and can be used only with heavily loaded polymer materials in which they replace the inert filler.

A more general approach in condensed phase fire retardancy involves the formation of a protective layer on the surface of the polymer material on heating which could prevent heat and mass transfer between the burning polymer and the flame. Diffusion of flammable volatiles towards the flame and of oxygen towards the polymer would thus be slowed down with the overall effect of reducing the rate and heat of combustion. This combined with a decrease of heat transfer from the flame to the polymer, removes the system from conditions conducive to self-sustainable combustion.

This approach has been pursued for some years now with the so called "intumescent systems" in which a foamed multicellular charred layer is built on the surface of the burning material. In polymers which do not char on heating, like polyolefins, the intumescent behaviour is obtained by means of multicomponent additives which include a char source (e.g., a polyhydric compound or a charring polymer), a charring catalyst 
(e.g., polyphosphoric acid precursor) and a blowing agent (e.g., melamine salt). In charring polymers the intumescent behaviour is promoted by additives that induce the formation of the cellular structure. Commercial intumescent fire retardant additives are now available whose effectiveness is not yet completely satisfactory and is highly variable with the nature of the basic polymer matrix.

A more recent approach involves the use of graphite, intercalated with a compound that volatilises on heating (e.g., sulphuric acid, see Fig. 1) at a temperature matching that of the thermal decomposition of the polymer [1-5].

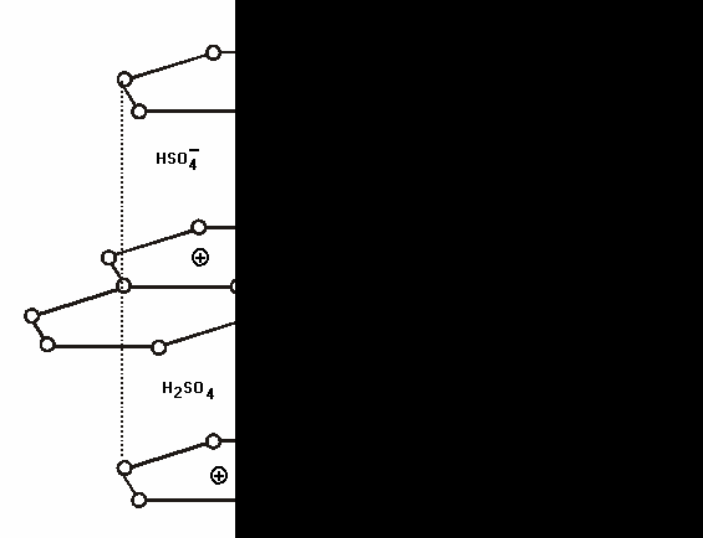

Fig. 1. Structure of $\mathrm{H}_{2} \mathrm{SO}_{4}$ graphite acid salt.

The volatilization of the intercalated moiety, expands the graphite layers (see Fig. 2) thus building the expanded and thermally stable structure on the surface of the polymer, made of graphite layers, that protects the polymer matrix.

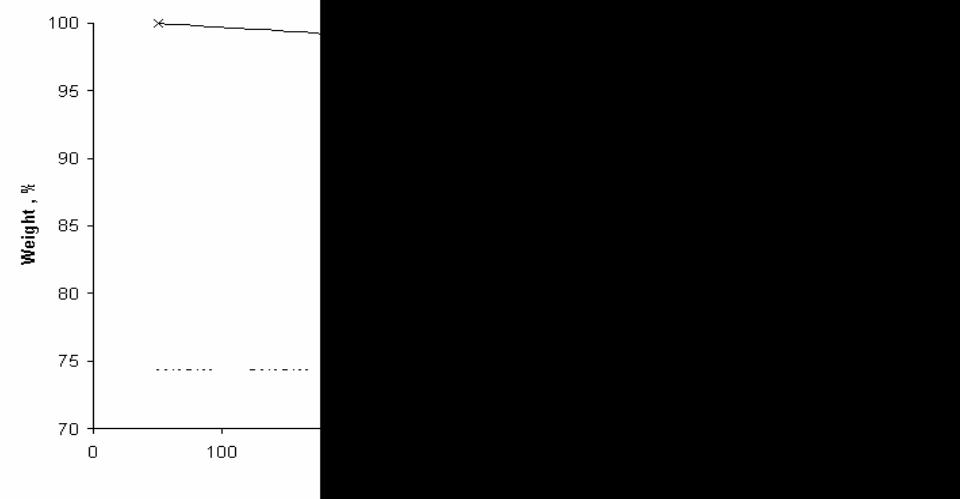

Fig. 2. Thermogravimetry (__) and blowing measurement (- -) of expandable graphite.

In the case of sulphuric acid as the intercalated moiety, expansion of the graphite is increased by partial oxidation of the carbon structure of the polymer by the oxidizing acid which also produces gases ostensibly acting as a blowing agent [1]. 
The use of expandable graphite, either alone or in combination with traditional fire retardants, seems promising although it is presently limited to the case of materials that can be colored in black. In some cases the effect of this can be reduced by the introduction of complementary pigments or through the application of the flame retardant treatment to a part of the product that is not visible, e.g., as a back coating.

The most recent attempt to create surface protection on a burning polymer material is that of dispersing an inorganic filler at nanodimensions (nanocomposites) into the polymer matrix which will accumulate on the surface of the material by polymer thermal ablation. Depending on the aspect ratio and capability of the nanoparticle to create a continuous ceramicised surface, a barrier is created between the polymer and the flame which slows down polymer combustion and potentially leads to flame extinguishment [6-18].

\section{NANOCOMPOSITES AND FIRE RETARDANTS}

In the last decade, methods have been developed to prepare and characterize nanocomposites of different aspect ratios with nanosize in three dimensions (particles: silica, polyhedralsilsesquioxanes POSS, etc.), two dimensions (tubes, e.g., carbon nanotubes, needle-like clays, wiskers, etc.), or one dimension (lamellar inorganics: phillosilicates/clays, hydrotalcites, phosphates, etc.). The dimension(s) which is (are) not in the nanosize range, can reach the micron size range with an aspect ratio that is about 1.000 in two dimensional and mono-dimensional nanosize fillers.

Typical morphologies obtained for example in the case of the lamellar nanocomposites, see Fig. 3, clearly indicate that the interface of contact between the inorganic and the organic phase is increased to the extent that the inorganic phase is now present almost exclusively as an "interphase," that is the phase of molecular size where chemical interactions between the phases are created and have an effect on the macroscopic properties of the composites. This means that in nanocomposites bulk properties of the inorganics are absent and the macroscopic properties of the nanocomposites are completely dependent on the structure of the interphase.

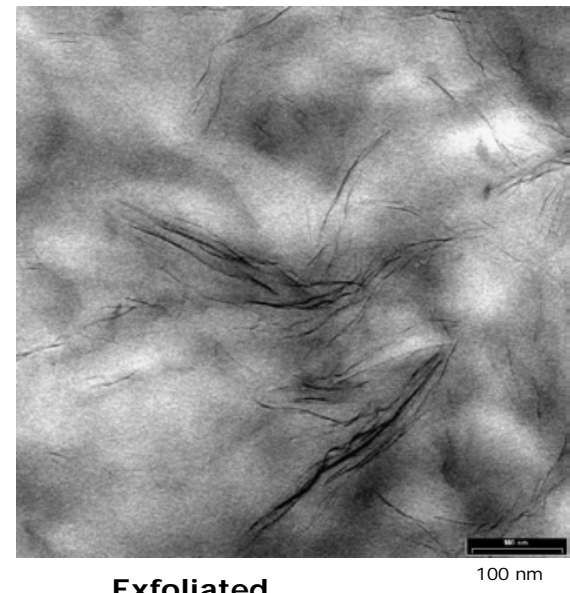

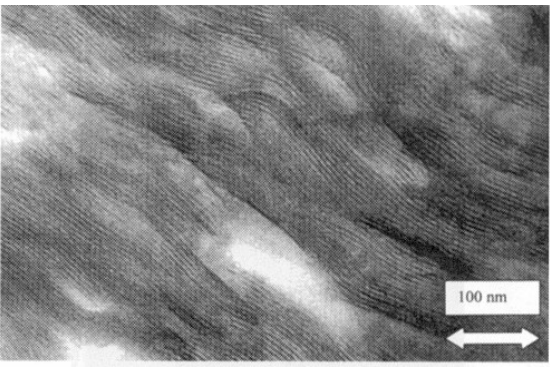

I ntercalated

Fig. 3. Exfoliated and intercalated morphology of lamellar nanocomposites by Transmission Electron Microscopy 


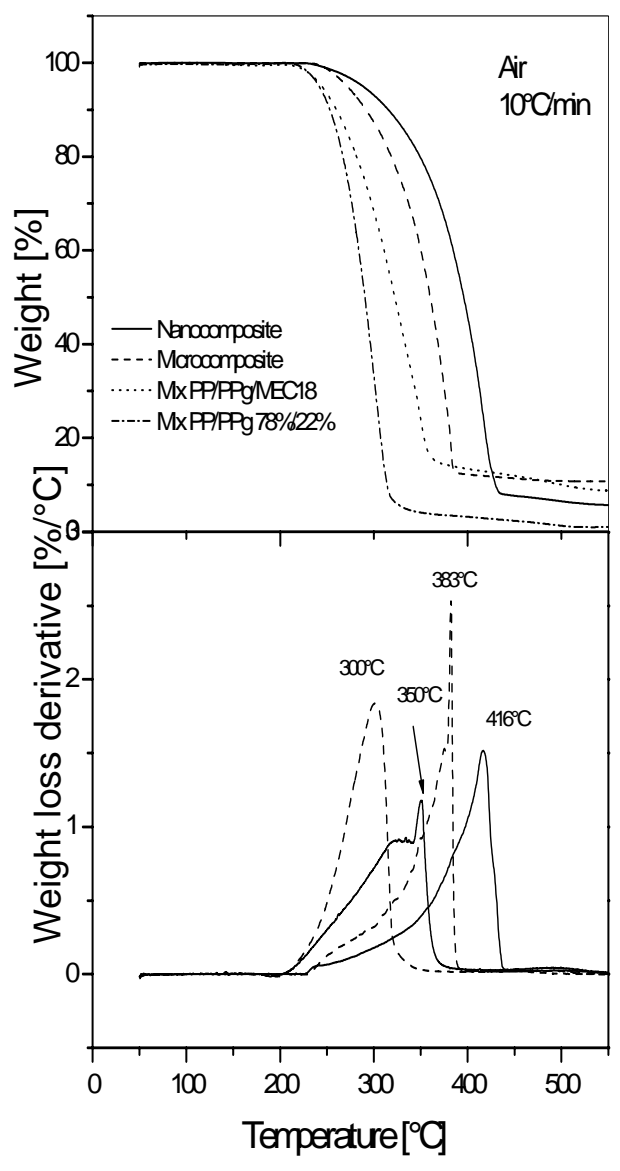

Fig. 4. Thermogravimetry in air of polypropylene (PP) composites and nanocomposites.

The morphology characteristics of nanocomposites explain their properties which are surprising since they cannot be extrapolated simply from macro and microcomposites as a function of the inorganic particles size. Thus, a number of mechanical and physical properties are improved by relatively small (weight) amounts of nanofillers (typically $<10 \% \mathrm{w} / \mathrm{w}$ ). In particular, the rate of combustion of the polymer matrix in nanocomposites is strongly reduced because polymer ablation rapidly leads to surface ceramicisation because of the fine dispersion of the ceramic phase

The barrier properties of the ceramicised surface are evident from the protection towards thermal oxidation that can be easily detected in nanocomposites in which the polymer matrix thermal degradation would be strongly accelerated if oxygen could diffuse freely in the material such as in the case of polypropylene. Figure 4 shows that the temperature for the maximum rate of volatilization of the polyprolpylene matrix is increased by $114^{\circ} \mathrm{C}$ going from pure polymer to a $10 \%$ loaded lamellar nanocomposite. 
A further aspect of the thermal behaviour of nanocomposites which can become relevant to fire retardancy is the tendency of nanocomposites to promote charring of the polymer matrix during combustion as shown in Fig. 5.
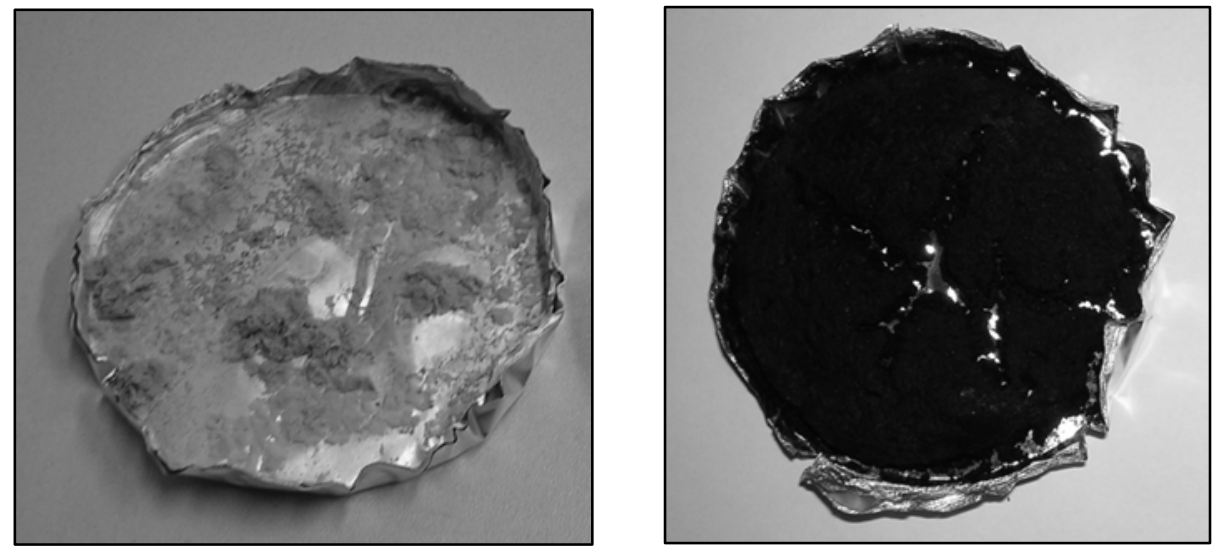

Fig. 5. Residues of combustion in the Cone calorimeter of Nylon 6 (left) and Nylon 6 nanocomposite (right).

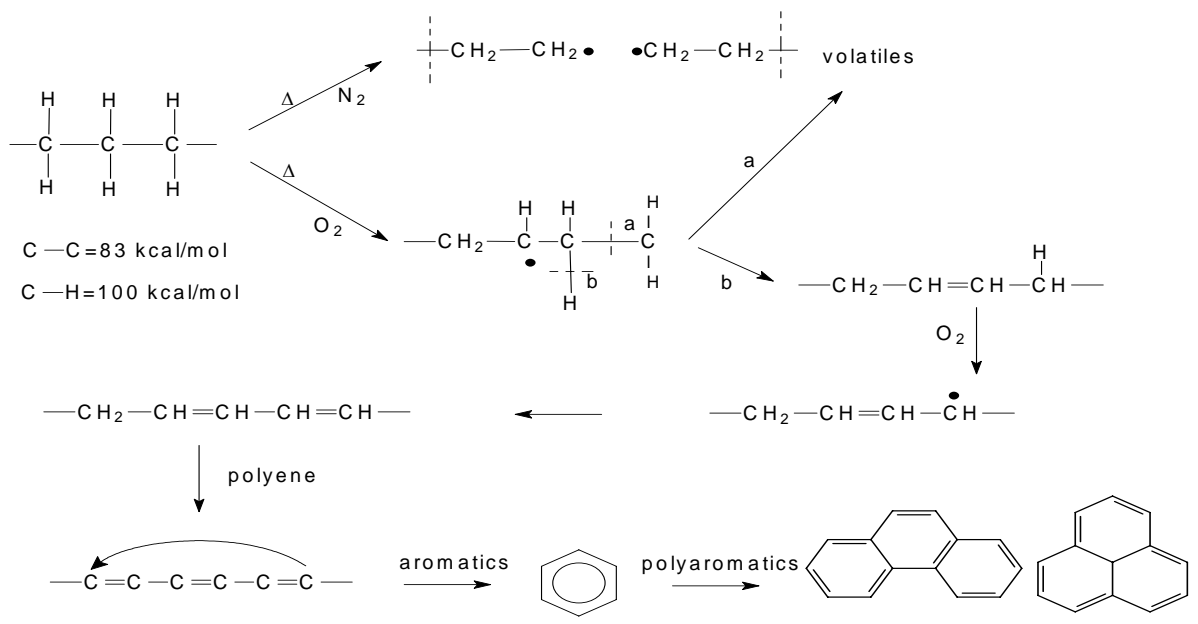

Fig. 6. Volatilisation versus charring in polyolefins thermal degradation.

Charring of the polymer matrix is the ultimate target for fire retardants since it allows the use of the material at working temperature whereas, in the presence of an accidental source of heat at high temperatures the material would rapidly char with a limited production of combustible volatiles. This is a most difficult task in linear polymers, particularly in polyolefins, because the temperature required for thermal scission of the carbon-carbon bonds of the chain is low compared to the other bonds as shown in Fig. 6 . Therefore, chain fragmentation to volatiles would be the most likely process to take place 
on heating polyolefins. Charring requires carbon-hydrogen bond scission which, in the case of polyolefins, is thermodynamically unfavoured. However, in the presence of oxygen, oxidative dehydrogenation can compete with chain scission with formation of unsaturations and of conjugated unsaturations which can evolve towards aromatic stable structures typical of charred organic materials as illustrated in Fig. 6. In nanocomposites, oxidative dehydrogenation can be catalysed to increase charring of the polymer as shown by isothermal thermogravimetry of polypropylene in Fig. 7.

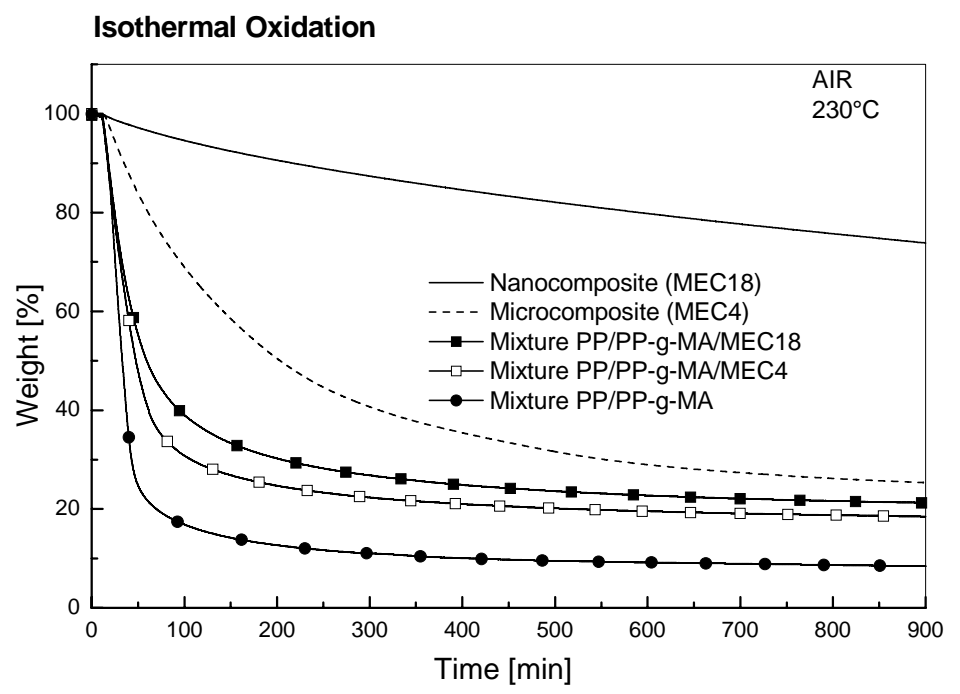

Fig. 7. Isothermal thermogravimetry of polypropylene composites and nanocomposites.

\section{CONCLUSIONS}

Therefore in conclusion, the mechanism of fire retardancy in nanocomposites is likely to involve a dual effect: a physical barrier to heat and mass transfer due to surface ceramicisation and a chemical catalytic effect promoting charring of the polymer matrix. Thus, the combustion of a typical lamellar nanocomposite could be depicted as in Fig. 8. Therefore, if we learn how to maximise these two effects in polymer nanocomposites we are close to the production of polymer materials which are not only protected from fire by a meaningful safe scientific approach but would also be characterised by improved mechanical and physical properties. 


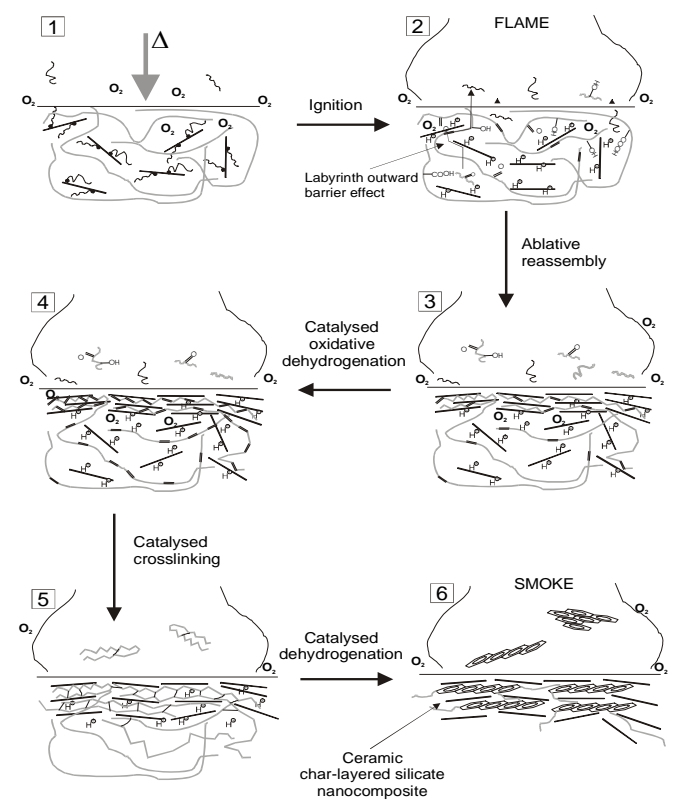

Fig. 8. Schematic representation of the combustion of a lamellar nanocomposite.

\section{ACKNOWLEDGEMENTS}

The Author wishes to thank Dr. Margaret Simonson of SP Swedish National Testing and Research Institute-Fire Technology for kindly revising this paper.

\section{REFERENCES}

[1] Camino, G., Duquesne, S., Delobel, R., Eling, B., Lindsay, C., and Roels, T. "Mechanism of Expandable Graphite Fire Retardant Action in Polyurethanes," ACS Symp. Ser. 797, 90-109 (2001).

[2] Duquesne, S., Le Bras, M., Bourbigot, S., Delobel, R., Camino, G., Eling, B., Lindsay, C., and Roels, T., "Thermal Degradation of Polyurethane and Polyurethane/Expandable Graphite Coatings," Polymer Degradation and Stability, 74, 493-499 (2001).

[3] Modesti, M., Lorenzetti, A., Simioni, F., and Camino, G., "Expandable Graphite as an Intumescent Flame Retardant in Polyisocyanurate-polyurethane Foams," Polymer Degradation and Stability, 77, 195-202 (2002).

[4] Duquesne, S., Delobel, R., Le Bras, M., and Camino, G., “A Comparative Study of the Mechanism of Action of Ammonium Polyphosphate and Expandable Graphite in Polyurethane,” Polymer Degradation and Stability, 77, 333-344 (2002).

[5] Duquesne, S., Le Bras, M., Bourbigot, S., Delobel, R., Vezin, H., Camino, G., Eling, B., Lindsay, C., and Roels, T., "Expandable Graphite: a Fire Retardant Additive for Polyurethane Coatings,” Fire and Materials, 27, 103-117 (2003). 
[6] Zanetti, M., Lomakin, L.S., and Camino, G., "Polymer Layered Silicate Nanocomposites," Macromolecular Materials and Engineering, 279, 1-9 (2000).

[7] Zanetti, M., Camino, G., Reichert, P., and Mülhaupt, R., "Thermal Behaviour of Polypropylene Layered Silicate Nanocomposites," Macromolecular Rapid Communications, 22, 176-180 (2001).

[8] Zanetti, M., Camino, G., Thomann, R., and Mülhaupt, R., "Synthesis and Thermal Behaviour of Layered Silicate-EVA Nanocomposites," Polymer, 42, 4501-4507 (2001).

[9] Zanetti, M., Camino, G. and Mülhaupt, R., "Combustion Behaviour of EVA/Fluorohectorite Nanocomposites,” Polymer Degradation and Stability, 74,413-417 (2001).

[10] Zanetti, M., Camino, G., Canavese, D., Morgan, A.B., Lamelas, F.J., and Wilkie, C.A., "Fire Retardant Halogen-antimony-clay Synergism in Polypropylene Layered Silicate Nanocomposites," Chemistry of Materials, 14(1), 189-193, (2002).

[11] Riva, A., Zanetti, M., Braglia, M., Camino, G., and Falqui, L., "Thermal Degradation and Rheological Behaviour of EVA/Montmorillonite Nanocomposites,” Polymer Degradation and Stability, 77, 299-304 (2002).

[12] Zanetti, M., Kashiwagi, T., Falqui, L., and Camino, G., "Cone Calorimeter Combustion and Gasification Studies of Polymer Layered Silicate Nanocomposites," Chemistry of Materials, 14, 881-887, (2002).

[13] Berta, M., Lindsay, C., Pans, G., and Camino, G., "Effect of Chemical Structure on Combustion and Thermal Behaviour of Polyurethane Elastomer Layered Silicate Nanocomposites," Polymer Degradation and Stability, accepted for publication.

[14] Pastore, H.O., Frache, A., Boccaleri, E., Marchese, L., and Camino, G., "Heat Induced Structure Modifications in Polymer-Layered Silicate Nanocomposites,” Macromolecular Materials and Engineering, 289 (2004) 783-786.

[15] Fina, Tabuani, D., Frache, A., Boccaleri, E., and Camino, G., "Isobutyl POSS thermal degradation," Fire Retardancy of Polymers: New Applications of Mineral Fillers Le Bras M., Wilkie C., Bourbigot S., Duquesne, S., Jama C. (eds.), The Royal Society of Chemistry, Cambridge, UK, 2005, Chapter 15, page 202-219.

[16] Gianelli, W., Camino, G., Tabuani, D., Bortolon, V., Savadori, T., and Ponticelli, O., "Flammability Properties of Polyester Nanocomposites," Fire and Materials, in press.

[17] Camino G., Tartaglione G. , Frache A. , Manferti C., and Falqui L., "Thermal and Combustion Behaviour of Layered Silicate-epoxy Nanocomposites," Polymer Degradation and Stability, in press.

[18] Fina, Tabuani, D., Frache, A., and Camino, G., "Polypropylene- Polyhedral Oligomeric SilSesquioxanes (POSS) Nanocomposites," Polymer, in press. 
[19] Camino, G., Tartaglione, G., Frache, A., Manferti, C., Finocchiaro, P., and Falqui, L., "Combined Fire Retardant Action of Phosphonated Structures and Clays Dispersion in Epoxy Resin," accepted 228 ${ }^{\text {th }}$ ACS National Meeting.

[20] Costantino, U., Gallipoli, A., Rocchetti, M., Camino, G., Bellucci, F., and Frache, A., "New Nano-composites Constituted of Polyethylene and Organically Modified ZnAl- hydrotalcites," Polymer Degradation and Stability, in press.

[21] Arena, U., Mastellone, M.L., Camino, G., and Boccaleri, E. "Multi-wall Carbon Nanotubes Production by Thermal Treatments of Polyolefines," Polymer Degradation and Stability, accepted. 